DOI 10.37882/2223-2982.2020.05.19

\title{
ГОТОВНОСТЬ БАКАЛАВРОВ ПЕДАГОГИЧЕСКОГО ОБРАЗОВАНИЯ К РАБОТЕ В УСЛОВИЯХ ИНКЛЮЗИВНОЙ СРЕДЫ
}

\section{READINESS OF BACHELORS \\ OF PEDAGOGICAL EDUCATION \\ FOR WORK IN THE CONDITIONS \\ OF AN INCLUSIVE ENVIRONMENT}

O. Lipunova

Summary: Readiness of Bachelors of pedagogical education for work in the conditions of an inclusive enviroment. An annotation: the problem of the formation of professional competence of future teachers to implement the objectives of inclusive education is considered. The results of the study of the formation of the components of inclusive competency in bachelors of teacher education are presented. Based on the analysis of the problem of the formation of professional competence of future teachers to implement the tasks of inclusive education, the components of the inclusive competence of future teachers for the implementation of the tasks of inclusive education are revealed. The analysis of the formation of the components of the inclusive competence of future teachers for working with children with disabilities in educational institutions is carried out.

Keywords: inclusive environment, professional competence, inclusive competence, children with disabilities, general professional, professional competencies.

\author{
Липунова Ольга Владимировна \\ K.nсх.н., дочент, ФГБОУ ВО «Амурский гуманитарно- \\ педагогический государственный университет» \\ (2. Комсомольск-на-Амуре) \\ belousowa29@mail.ru
}

Аннотация: Рассмотрена проблема формирования профессиональной компетентности будущих педагогов для реализации задач инклюзивного образования. Изложены результаты исследования сформированности компонентов инклюзивной компетентности у бакалавров педагогического образования. На основе анализа проблемы формирования профессиональной компетентности будущих педагогов для реализации задач инклюзивного образования раскрыты компоненты инклюзивной компетентности будущих педагогов для реализации задач инклюзивного образования. Проведен анализ сформированности компонентов инклюзивной компетентности будущих педагогов для работы с детьми с ограниченными возможностями здоровья в образовательных учреждениях.

Ключевые слова: инклюзивная среда, профессиональная компетентность, инклюзивная компетентность, дети с ограниченными возможностями здоровья, общепрофессиональные, профессиональные компетенции
И зменения в социально-экономической, политической жизни общества на современном этапе его развития предъявляют все более высокие требования к профессиональным знаниям и личности педагога, требуют от педагога решения задач, связанных с созданием условий для эффективной интеграции людей с особыми образовательными потребностями в общество $[1 ; 3 ; 9 ; 12]$.

Современный этап развития инклюзивного процесса в российском образовании характеризуется сложившейся государственной политикой в сфере образования детей с ограниченными возможностями здоровья, установлением основных механизмов и норм реализации идеи инклюзии, утверждением федеральных государственных образовательных стандартов для детей с ограниченными возможностями здоровья, реализацией принципа равных социальных прав и возможностей. Одним из условий полноценной интеграции лиц с ограниченными возможностями здоровья в общество является устранение социальных и психологических барьеров приобретения достойного социального статуса, оптимального качества жизни. При этом, по мнению со- временных исследователей, образование будет инклюзивным только в том случае, если идея инклюзии будет осмыслена и принята педагогом и станет характеристикой образовательного процесса [1].

Профессиональное образование в современных условиях в достаточной мере не решает проблему дефицита кадров для формирования инклюзивной образовательной среды. Актуальными являются вопросы подготовки конкурентоспособных специалистов, работающих в системе специального и инклюзивного образования и владеющих коррекционно-развивающими технологиями работы с детьми с ограниченными возможностями здоровья $[2 ; 6 ; 11]$.

Педагоги образовательных организаций общего типа испытывают характерные трудности сопровождения детей с ограниченными возможностями здоровья с учетом их особых образовательных потребностей, т.к. не владеют в полной мере специальными знаниями и практическими навыками [5].

Профессиональную компетентность в современных 
исследованиях определяют как систему знаний, умений и навыков, а также профессионально-значимых качеств личности, обеспечивающих выполнение профессиональных обязанностей $[7 ; 8 ; 9]$.

По мнению современных исследователей, личностная и профессиональная готовность педагогов включает установки, мотивы, качества, обеспечивающие толерантное отношение к лицам с ограниченными возможностями здоровья, а также совокупность психолого-педагогических знаний, практических умений и навыков:

- о сущности инклюзивного образования и его принципиальных отличиях от традиционного образования;

- об особенностях психологического, возрастного и личностного развития детей в норме и с ограниченными возможностями здоровья;

- о содержании методов психолого-педагогического проектирования учебного процесса для совместного обучения детей с нормой и особыми образовательными потребностями;

- о технологиях педагогического взаимодействия между всеми субъектами образовательной среды (учащиеся, родители, коллеги-учителя, специалисты, руководство) [7].

В качестве основополагающих компонентов инклюзивной компетентности выделяют мотивационный, когнитивный, рефлексивный и операционный компоненты.

Мотивационный компонент включает повышение активности и личностной заинтересованности специалиста инклюзивного образования в осуществлении педагогической деятельности в условиях совместного обучения нормально развивающихся сверстников и детей с ограниченными возможностями здоровья.

Когнитивный компонент рассматривается как способность педагогически мыслить, выделять и подвергать анализу различные аспекты решения проблем инклюзивного образования.

Рефлексивный компонент включает способности анализировать собственную учебную, практическую и профессиональную деятельность в процессе внедрения опыта совместного обучения детей с ОВ3 и нормой развития.

В содержание операционного компонента входят инклюзивные технологии, необходимые для решения возникших педагогических ситуаций, осуществления поисково-исследовательской деятельности [10].

Как показывает практика, новые стандарты образования требуют от педагога высокого уровня инклюзивной компетентности. Этапы формирования инклюзивной компетентности включают: научно-познавательный этап, предполагающий освоение студентами теорий, методик, технологий психолого-педагогического сопровождения детей с ограниченными возможностями здоровья; мотивационный, формирующий толерантное отношение к участникам образовательного процесса, профессиональные гуманистические ценности, деятельно-преобразующий, включающий студентов в практическую (квазипрофессиональную) деятельность [4].

Согласно ФГОС, у выпускника должны быть сформированы общепрофессиональные и профессиональные компетенции, соответствующие содержанию педагогической деятельности.

В ряде формируемых компетенций (ОПК-2, ПК-1, ПК2, ПК-53, ПК-6 и др.) ФГОС ВО 44.03.01 Педагогическое образование (уровень бакалавриата), 44.03 .05 - Педагогическое образование (с двумя профилями подготовки) актуализируются различные компоненты инклюзивной компетентности в подготовке бакалавров педагогического образования: мотивационный, когнитивный, рефлексивный и операционный.

Когнитивный и операционный компоненты инклюзивной компетентности предполагают способность осуществлять коррекционно-образовательный процесс, дифференцированно выбирать и использовать методическое и техническое обеспечение с учётом особых образовательных потребностей и психофизических возрастных особенностей обучающихся с ОВ3, реализовывать специальные знания в своей профессиональной деятельности.

Мотивационный и рефлексивный компоненты отражают сформированность способности к саморазвитию, осознанию и реализации собственной мировоззренческой и гражданской позиций, развитие мотивации к проектированию и осуществлению профессиональной деятельности с лицами с ОВ3, готовности сознавать социальную значимость своей профессии.

ФГБОУ ВО «АмГПГУ» в рамках высшего образования (уровень бакалавриата) реализует основные профессиональные образовательные программы педагогического образования.

Целью исследования явился анализ компонентов инклюзивной компетентности будущего педагога: мотивационного (сформированность мотивации и внутренней готовности к позитивному восприятию обучающихся С ограниченными возможностями здоровья), когнитивного (сформированность знаний об особенностях психического и физического развития детей с ограниченными возможностями здоровья, особенностях организации педагогического процесса по сопровождению обучающихся с ОВ3), рефлексивного (способность к рефлексии, творческой активности) и операционного (готовность к 
реализации профессионально-педагогических знаний в работе с детьми с ограниченными возможностями здоровья).

С целью исследования готовности студентов-выпускников педагогического вуза к работе с детьми с ограниченными возможностями здоровья мы использовали метод письменного опроса - анкетирование, была разработана анкета для анализа компонентов инклюзивной компетентности будущего педагога к работе с детьми с ограниченными возможностями здоровья.

В анкетировании приняли участие студенты выпускных курсов ФГБОУ ВО «Амурский гуманитарно-педагогический государственный университет», обучающиеся по направлению подготовки 44.03.01 «Педагогическое образование», 44.03 .05 - «Педагогическое образование (с двумя профилями подготовки)».

Анализ сформированности мотивировационного компонента инклюзивной компетентности у исследуемых студентов свидетельствует о том, что у большинства исследуемых будущих педагогов сформированы мотивы к работе с детьми с ограниченными возможностями здоровья, что проявляется в готовности выпускников осуществлять процесс обучения, воспитания детей с ограниченными возможностями здоровья, в готовности К позитивному восприятию обучающихся с ограниченными возможностями здоровья.
Ряд вопросов анкеты по содержанию (сформированы ли у студентов представления о понятии «дети с ОВЗ», о группах детей с отклонениями в развитии, об особенностях психического развития детей с ограниченными возможностями здоровья, о недостатках развития, характерных для всех категорий детей с ограниченными возможностями здоровья) позволил осуществить анализ сформированности у исследуемых будущих педагогов когнитивного и операционного компонентов инклюзивной компетентности.

Количественный анализ сформированности у исследуемых студентов знаний и представлений об особенностях психического развития детей с ограниченными возможностями здоровья - когнитивного компонента инклюзивной компетентности представлен в таблице 1.

Согласно представленным в таблице 1 данным, все исследуемые студенты в той или иной степени имеют представление о категории детей с ограниченными возможностями здоровья.

Ряд вопросов анкеты по содержанию (знание инклюзивных технологий, необходимых для решения возникающих педагогических ситуаций, необходимость осуществления в связи с этим поисково-исследовательской деятельности) позволил осуществить анализ сформированности у исследуемых студентов знаний и представлений об условиях обучения и воспитания детей с ограниченными возможностями здоровья, о специфике

Представления испытуемых об особенностях психического развития детей

Таблица 1 с ограниченными возможностями здоровья

\begin{tabular}{|c|c|c|c|c|c|c|c|c|c|c|c|c|}
\hline \multirow[b]{3}{*}{ Группа } & \multicolumn{4}{|c|}{ Знакомы ли с понятием «дети с ОВЗ» } & \multicolumn{4}{|c|}{$\begin{array}{c}\text { Имеют ли представления о группах детей } \\
\text { с отклонениями в развитии }\end{array}$} & \multicolumn{4}{|c|}{$\begin{array}{c}\text { Имеют ли представления об особенностях } \\
\text { психического развития детей с ОВ3 }\end{array}$} \\
\hline & \multicolumn{2}{|c|}{ да } & \multicolumn{2}{|c|}{ нет } & \multicolumn{2}{|c|}{ да } & \multicolumn{2}{|c|}{ нет } & \multicolumn{2}{|c|}{ да } & \multicolumn{2}{|c|}{ нет } \\
\hline & абс. & $\%$ & абс. & $\%$ & абс. & $\%$ & абс. & $\%$ & абс. & $\%$ & абс. & $\%$ \\
\hline ПОноия-55 & 6 & 37,5 & 10 & 62,5 & 11 & 68,8 & 5 & 31,2 & 6 & 37,5 & 10 & 62,5 \\
\hline П06x-55 & 4 & 66,7 & 2 & 33,3 & 4 & 66,7 & 2 & 33,3 & 2 & 33,3 & 4 & 66,7 \\
\hline Побжиг-41 & 4 & 66,7 & 2 & 33,3 & 4 & 66,7 & 2 & 33,3 & 1 & 16,7 & 5 & 83,3 \\
\hline ПОдо-44 & 5 & 55,5 & 4 & 44,5 & 9 & 100 & 0 & 0 & 3 & 33,9 & 6 & 66,7 \\
\hline
\end{tabular}

Представления испытуемых об особенностях педагогического сопровождения детей с ограниченными возможностями здоровья

\begin{tabular}{|c|c|c|c|c|c|c|c|c|c|c|c|c|}
\hline \multirow[b]{3}{*}{ Группа } & \multicolumn{4}{|c|}{$\begin{array}{c}\text { Имеют ли представления } \\
\text { об условиях обучения и воспитания детей } \\
\text { С ОВ3 }\end{array}$} & \multicolumn{4}{|c|}{$\begin{array}{c}\text { Имеют ли представления о специфике } \\
\text { методов обучения и воспитания детей } \\
\text { С ОВ3 }\end{array}$} & \multicolumn{4}{|c|}{$\begin{array}{c}\text { Имеют ли представления о формах } \\
\text { организации специального обучения и } \\
\text { воспитания детей с } 0 \mathrm{~B} 3\end{array}$} \\
\hline & \multicolumn{2}{|c|}{ да } & \multicolumn{2}{|c|}{ нет } & \multicolumn{2}{|c|}{ да } & \multicolumn{2}{|c|}{ нет } & \multicolumn{2}{|c|}{ да } & \multicolumn{2}{|c|}{ нет } \\
\hline & абс. & $\%$ & абсc. & $\%$ & абс. & $\%$ & абс. & $\%$ & абсc. & $\%$ & абс. & $\%$ \\
\hline ПОноия-55 & 3 & 18,8 & 13 & 81,2 & 2 & 12,5 & 14 & 87,5 & 1 & 6,2 & 15 & 93,8 \\
\hline П06х-55 & 1 & 16,7 & 5 & 83,3 & 0 & 0 & 6 & 100 & 0 & 0 & 6 & 100 \\
\hline ПОбжиг-41 & 0 & 0 & 6 & 100 & 0 & 0 & 6 & 100 & 0 & 0 & 6 & 100 \\
\hline ПОдо-44 & 2 & 22,2 & 7 & 77,8 & 2 & 22,2 & 7 & 77,8 & 1 & 11,1 & 8 & 88,9 \\
\hline
\end{tabular}


методов обучения и воспитания детей с ограниченными возможностями здоровья, о формах организации специального обучения и воспитания детей с ограниченными возможностями здоровья.

Количественный анализ результатов исследования сформированности операционного компонента компетентности представлен в таблице 2.

Как видно из таблицы 2, у значительной части исследуемых студентов не сформированы представления об условиях, которые необходимо соблюдать при воспитании и обучении детей с ограниченными возможностями здоровья. Также, согласно анализу результатов исследования, у подавляющего большинства исследуемых студентов не сформированы представления о специфике методов обучения и воспитания детей с ограниченными возможностями здоровья. Согласно представленным в таблице 2 результатам, у подавляющего большинства исследуемых студентов не сформированы представления о формах организации специального обучения и воспитания детей с ограниченными возможностями здоровья. На наш взгляд, полученные результаты свидетельствуют о несформированности у будущих педагогов операционного компонента инклюзивной компетентности, неготовности осуществления поисково-исследовательской деятельности.

Исследование сформированности рефлексивного компонента компетентности (способность анализировать собственную учебную, практическую и профессиональную деятельность в процессе внедрения опыта совместного обучения детей с ОВ3 и нормой развития), предполагало анализ ответов испытуемых на вопрос о том, считают ли студенты достаточным уровнем собственной профессиональной подготовки для дальнейшей работы с детьми с ограниченными возможностями здоровья.

Количественный анализ результатов исследования представлен в таблице 3.

Таблица 3

Представления испытуемых об уровне собственной профессиональной подготовки для дальнейшей работы с детьми с ограниченными возможностями здоровья

\begin{tabular}{|l|c|c|c|c|}
\hline \multicolumn{3}{|}{$\begin{array}{r}\text { Уровень собственной профессиональной готовности для дальнейшей } \\
\text { работы с детьми с ограниченными возможностями здоровья }\end{array}$} \\
\hline $\begin{array}{r}\text { Варианты } \\
\text { ответов }\end{array}$ & \multicolumn{2}{|c|}{ достаточный } & \multicolumn{2}{|c|}{ недостаточный } \\
\cline { 2 - 5 } Группа & абс. & $\%$ & абс. & $\%$ \\
\hline П0ноия-55 & 1 & 6,2 & 15 & 93,8 \\
\hline П0бх-55 & 0 & 0 & 6 & 100 \\
\hline П0бжиг-41 & 0 & 0 & 6 & 100 \\
\hline П0д0-44 & 1 & 11,1 & 8 & 88,9 \\
\hline
\end{tabular}

Согласно анализу полученных результатов, представ- ленных в таблице 3, большинство из исследуемых групп считают недостаточным свой уровень профессиональной подготовки для работы с детьми с ограниченными возможностями здоровья.

Полученные результаты свидетельствуют о том, что в целом исследуемые студенты имеют представление о детях с ограниченными возможностями здоровья, при этом у будущих педагогов не в полной мере сформированы представления об особенностях детей с ограниченными возможностями, а также закономерностях их развития и особых потребностях при каждом варианте нарушенного развития.

Также полученные результаты свидетельствуют о том, что у будущих педагогов не сформированы представления об особенностях психического развития детей с ограниченными возможностями здоровья; о недостатках развития, характерных для детей с ограниченными возможностями здоровья; об особенностях организации педагогической работы с детьми с ограниченными возможностями здоровья; об условиях сопровождения детей с ограниченными возможностями здоровья в образовательной организации. Также, исходя из анализа результатов исследования, будущие педагоги не владеют методами специального обучения и воспитания. Будущие педагоги высказывают опасения о необходимости работы с детьми с ограниченными возможностями здоровья, либо предпочитают вообще не сталкиваться с данной категорией детей в своей предстоящей профессиональной деятельности. Уровень своей профессиональной подготовки и личностной готовности для работы с детьми с ограниченными возможностями здоровья большинство из исследуемых будущих педагогов оценивают как недостаточный.

Результаты исследования свидетельствуют об актуальности проблемы и необходимости поиска путей повышения уровня инклюзивной компетентности студентов в вопросах инклюзивного образования.

На наш взгляд, для успешного формирования инклюзивной компетентности будущих педагогов в процессе профессиональной подготовки необходимо реализовывать следующие педагогические условия:

- расширение в использовании содержания базовых, вариативных дисциплин для формирования у будущих педагогов знаний о развитии, воспитании и обучении детей с ограниченными возможностями здоровья, об особенностях профессиональной деятельности педагога в системе инклюзивного образования;

- включение в программы производственных практик освоение студентами конкретных действий педагога в содержании практической професси- 
ональной деятельности в инклюзивной среде в условиях образовательных организаций;

- применение технологии контекстного обучения посредством эффективного соединения продуктивных и репродуктивных методов, с целью изменения содержания профессиональной деятельности по реализации инклюзивного образования для осознания студентами важности, понимания сущности проблемы и сложности работы с детьми с ограниченными возможностями здоровья.

Таким образом, компетентностный подход является ключевым принципом развития образования. Однако, согласно анализу результатов проведенного исследования, сформированные у выпускника-бакалавра компетенции не обеспечивают полноценной подготовки квалифицированного педагога для инклюзивной практики, многие будущие педагоги находятся на стадии явного или латентного сопротивления.

Показателями сформированной компонентов ин- клюзивной компетентности у студентов педагогического вуза являются теоретические знания, профессиональные умения, сформированность профессиональных мотивов и интересов, научно-исследовательская активность и самостоятельность, социальная и профессиональная толерантность, способность брать на себя ответственность за всех участников инклюзивной среды, целостное отношение к различным аспектам своей профессиональной деятельности, умение взаимодействовать с другими участниками образовательного процесca.

Идея инклюзивного образования, на наш взгляд, займет свое место в образовательном процессе только в том случае, если она станет составной частью профессионального мышления педагога. Для этого необходима реализация специальных условий подготовки студентов, чтобы изменить отношение у будущих педагогов к инклюзивному образованию как особой форме организации образовательного процесса.

\section{ЛИТЕРАТУРА}

1. Алехина С.В. Инклюзивное образование: от политики к практике // Психологическая наука и образование. 2016. Том 21. № 1. С. 136-145. doi:10.17759/ pse.2016210112

2. арынбаева 0.В. Подготовка педагогов в дополнительном профессиональном образовании к формированию инклюзивной образовательной среды в общеобразовательных организациях. Тольятти: ПГУ им. Шолом Алейхема, 2016. - 25 с.

3. Кузьмина 0.С. Актуальные вопросы подготовки педагогов к работе в условиях инклюзивного образования // Вестник Омского университета. 2013. № 2. C. $191-194$.

4. Мёдова Н.А. Формирование у студентов педагогического факультета профессиональной готовности к реализации инклюзивного образования // Вестник Томского гос. пед. ун-та (TSPU Bulletin). 2016. Вып. 5 (170). - С. 70-73.

5. Петрова Т.Н. Готовность студентов педагогического вуза к реализации инклюзивного образования в условиях ФГОС // Молодой ученый. - 2017. - №15. C. 617-619.

6. Рудакова Н.П., Денисова Р.Р. Подготовка бакалавров специального (дефектологического) образования к работе в условиях инклюзивной среды // Инклюзивное образование: тенденции, проблемы, перспективы: сборник материалов Всероссийской научно-практической конференции с международным участием (11-12 апреля 2019 г., Благовещенск). - Благовещенск: Издательство БГПУ, 2019. - С.11-15.

7. Сабельникова С.И. Программа коррекционной работы в образовательном учреждении - системный подход к развитию инклюзивного образования // Инклюзивное образование: методология, практика, технология: матер. Междунар. науч.-практ. конф. М., 2011. - С. 145-146.

8. Сергеева Н.Н. Комплексный подход к проблеме формирования профессиональной толерантности будущих учителей к детям с ограниченными возможностями здоровья / Н.Н. Сергеева, А. В. Демчук // Специальное образование. -2011.-№ 3.- С.111-118.

9. Филатова, И.А. Ценности специального педагога как основа формирования готовности к профессиональной деятельности / И.А.Филатова // Специальное образование. -2010.-N4.-C.43-49.

10. Хафизуллина И.Н. Формирование инклюзивной компетентности будущих учителей в процессе профессиональной подготовки [Текст]: дис. . . канд. пед. наук: 13.00.08: защищена 22.03.08 / Хафизуллина Ильмира Наильевна. - Астрахань, 2008. 213 с.

11. Хитрюк В.В. Формирование инклюзивной готовности будущих педагогов: результативность дидактической модели // Вестник Балтийского федерального университета им. И. Канта. 2015. № 5. С. 112-120.

12. Яковлева И.М. Профессионально-личностная готовность педагога к работе с детьми с ограниченными возможностями здоровья/ И. М. Яковлева // Вестник МгоПу Серия «Педагогика». - 2009. - № 6. - С. 140-144.

(c) Липунова Ольга Владимировна (belousowa29@mail.ru). 